\title{
Camphor Sulfonic Acid Catalyzed Facile and Atom Economical Access to Highly Substituted Piperidines via One Pot Multi Component Reactions
}

\author{
Mahendra Chaudhari, Jitendra Gujar, Vilas B Labade and Murlidhar Shingare* \\ Department of Chemistry, Dr. Babasaheb Ambedkar Marathwada University, India
}

Received: 制January 25, 2018; Published: 眥 February 09, 2018

*Corresponding author: Murlidhar Shingare, Department of Chemistry, Dr. Babasaheb Ambedkar Marathwada University, India, Tel: 91-2402403311; Fax: 91-2402403113; Email: msshingare@yahoo.com

\begin{abstract}
A simple and efficient protocol has been developed for the synthesis of highly substituted Piperidines derivatives. This strategy demonstrated five component reactions of two equivalents of aldehydes, two equivalents of anilines and $\beta$-keto esters in ethanol using $10 \mathrm{~mol} \%$ of camphor sulfonic acid at reflux. The significant features of the present protocol include excellent yield, shorter reaction time, and easy work up procedure, broad substrate scope, high atom economy and formation of C-C and C-N bond in a single step operation.
\end{abstract}

Keywords: Piperidines; Camphor sulfonic acid; Multi component reactions; High atom economy

\section{Introduction}

The Piperidines and its analogues represent one of the most prominent compound classes which are widely distributed in biologically active compounds, pharmaceuticals and natural products [1]. Several compounds possessing Piperidines scaffold have been reported to exhibit a wide range of valuable bioactive properties including antihypertensive, neuro-protective, antiinflammatory, antibacterial, anti malarial and anticonvulsant activities [2]. Also, some of Piperidines analogues possess enzyme inhibitory activity against farnesyl transferees and dihydroorotate dehydrogenase [3]. Especially, highly substituted Piperidines have been recognized as an important class of therapeutic agents in the treatment of cancer metastasis, influenza, Parkinson's disease, viral infections including AIDS and diabetes [4]. Recently, interest in the field of organ catalysis has enormously increased as a result of both the novelty of the concept and more importantly, the fact that the efficiency and selectivity of many organ catalytic reactions meet the standards of established organic reactions [5]. Examples of organ catalysis to accelerate organic reactions had been periodically reported in the literature for decades. These organic catalysts are inexpensive, readily available, low cost, non-toxic, biodegradable, and inert towards moisture and oxygen. Absences of transition metals make these protocols attractive for the synthesis of pharmaceutical products [6]. Search of an efficient organ catalyst for organic transformations remain a challenging task.

Recently, our group synthesized 1,5-benzodiazepine, $\alpha$-hydroxy and $\alpha$-amino phosphonates using camphor sulfonic acid as organ catalyst [7]. Also, camphor sulfonic acid (CSA) is achieving enormous significance in organic synthesis, as this catalyst is used in the synthesis of chromans, ligands, and pseudo glycosides, as an auxiliary and in some polymerization reactions [8]. So far, to the best of our knowledge, there is no report available on the use of camphor sulfonic acid as an organ catalyst for the synthesis of highly substituted Piperidines. The synthesis of such highly substituted Piperidines derivatives has gained considerable attention and are based on various reactions including- (a) cyclopropane ring opening/Conia-ene cyclization [9], (b) imino Diels-Alder reaction [10], (c) aza-Prins cyclizations [11], (d) intra molecular Michael reaction [12] and (e) intra molecular Mannich reaction onto iminium ions [13]. The pot atom step economic (PASE) synthesis of highly substituted Piperidines from relatively simple starting materials has been reported in the literature. Synthesis of highly substituted Piperidines involves three component reactions of two equivalents of aldehydes, two equivalents of anilines and one equivalent $\beta$-ketoesters. Boehm in 1943 reported the first 
multi component reaction between an amine, aldehydes and 1,3-dicarbonyl to synthesize functionalized piperidines [14]. Recently, the synthesis of highly substituted Piperidines has been reported using $\mathrm{InCl}_{3}$ [15], bromodimethylsulfonium bromide [16], tetrabutyl ammonium bromide [17], iodine [18], l-proline nitrate [19], thiourea dioxide [20] as catalysts.

One of the main challenges of synthetic chemists lies in the development and implementation of efficient methodologies for the synthesis of biologically significant scaffolds. However, methodologies reported for this reaction so far suffer from one or more shortcomings such as low yield, prolonged reaction time, use of toxic organic solvents, and requirement of excess of reagents or catalysts and harsh reaction conditions. Therefore, there is still a demand for the development of effective protocols for the expedient synthesis of highly substituted Piperidines under mild conditions using inexpensive catalysts. In view of the importance of all above discussed aspects and in continuation of our endeavor towards the development of synthetic methodologies for various organic transformations [21] it was thought to develop new and expeditious route for the synthesis of highly substituted piperidines using camphor sulfonic acid as an organ catalyst.

\section{Material and Methods}

\section{General}

All chemicals were purchased and used without any further purification. Progress of the reactions were monitored by thin layer chromatography (TLC) on silica gel plates $\left(60 \mathrm{~F}_{254}\right)$, visualizing with ultraviolet light. Melting points were recorded in open capillary tubes and are uncorrected. ${ }^{1} \mathrm{H}$ NMR and ${ }^{13} \mathrm{C}$ NMR spectra were recorded on a Bruker Avance 400 or $300 \mathrm{MHz}$ and Bruker DRX 75 or $100 \mathrm{MHz}$ spectrometer respectively. Chemical shift values $(\delta)$ are expressed in (parts per million) ppm relative to TMS. The electro spray mass spectra were recorded on a THERMO Finnigan LCQ Advantage max ion trap mass spectrometer.

\section{General experimental procedure for the synthesis of highly substituted Piperidines 4(a-n)}

Table 1: Synthesis of highly substituted piperidines ${ }^{\mathrm{a}}$.

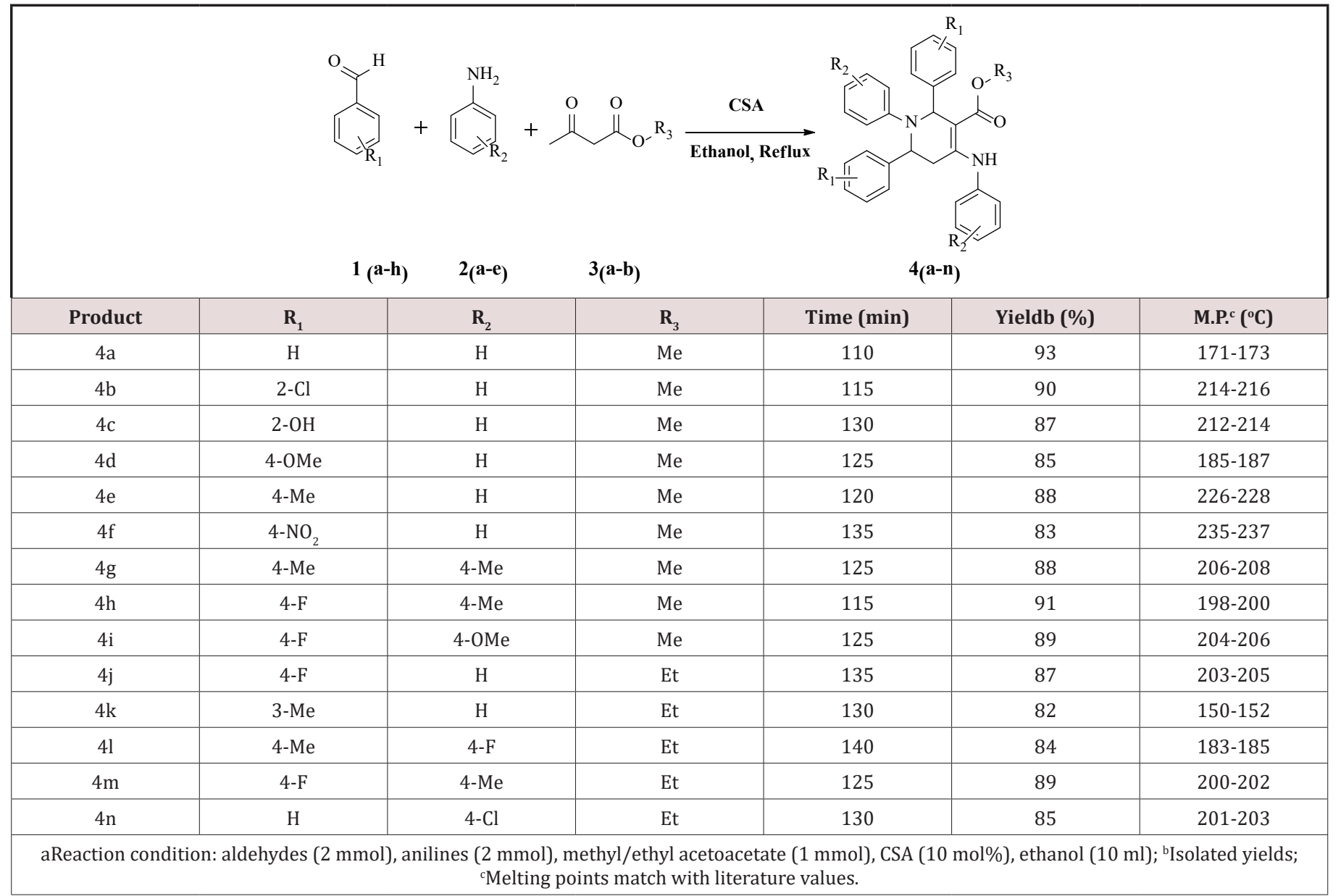

A mixture of aromatic aldehydes $(2 \mathrm{mmol})$, aromatic anilines ( $2 \mathrm{mmol}), \beta$-ketoesters ( $1 \mathrm{mmol})$ and camphor sulfonic acid $(10 \mathrm{~mol}$ $\%)$ in ethanol $(10 \mathrm{ml})$ was refluxed for appropriate time as shown in Table 1. Progress of the reaction was monitored by TLC on silica with n-hexane: ethyl acetate (7:3) as mobile phase. After completion of the reaction, the products was poured on crushed ice and filtered to obtain crude product. Further, solid product was re crystallized from ethanol to afford pure compound. 


\section{Spectral data for representative compound}

Methyl-2,6-bis(2-chlorophenyl)-1-phenyl-4-(phenylamino)1,2,5,6-tetrahydropyridine-3-carboxylate (4b): ${ }^{1} \mathrm{H}$ NMR $(400 \mathrm{MHz}$, DMSO-d $\left.{ }_{6}\right): \delta 9.96\left(\mathrm{~s},{ }^{1} \mathrm{H},-\mathrm{NH}\right), 7.47-7.42(\mathrm{~m}, 2 \mathrm{H}, \mathrm{Ar}-\mathrm{H}), 7.36-7.12$ (m, 8H, Ar-H), 7.08-7.02 (m, 3H, Ar-H), 6.62-6.59 (t, J = 7.2 Hz, 1H, Ar-H), 6.47- 6.45 (d, J = 7.6 Hz, 2H, Ar-H), 6.35 (s, 1H), 6.30 (d, J = $8.0 \mathrm{~Hz}, 2 \mathrm{H}, \mathrm{Ar}-\mathrm{H}), 5.48(\mathrm{t}, \mathrm{J}=4.0 \mathrm{~Hz}, 1 \mathrm{H}), 3.78(\mathrm{~s}, 3 \mathrm{H}), 2.96-2.92(\mathrm{~m}$, 2H); 13C NMR (100 MHz, DMSO-d $): \delta 167.6,154.8,146.3,144.0$, $142.8,137.5,128.9,128.8,128.7,128.4,128.3,127.0,126.4,126.2$, 126.1, 125.5, 124.8, 115.7, 112.3, 97.6, 56.6, 54.8, 51.1, 33.4; Mass (ES-MS) : m/z $529.2[\mathrm{M}+\mathrm{H}]+$

\section{Results and Discussion}

Initially, the reaction was performed with two equivalent of benzaldehyde (1a), two equivalents of aniline (2a) and one equivalent methyl acetoacetate (3a) in ethanol as the model substrates to find out the optimum reaction conditions (Scheme 1). When the reaction was carried out in the absence of catalyst, the product formed in very trace amount at room temperature and reflux (Table 2, entries 1-2). The yield of 4 a was achieved with a maximum (93\%) (Figure 1). When the reaction was carried out with the use of $10 \mathrm{~mol} \%$ of camphor sulfonic acid in ethanol at reflux for $110 \mathrm{~min}$ (Table 2, entry 4). Subsequent screening of the various catalysts revealed that CSA exhibited superior results, while sulphuric acid, p-toluene sulfonic acid, glycine, polystyrene Table 2: Screening and effect of concentration catalyst ${ }^{\mathrm{a}}$. supported $\mathrm{p}$-toluene sulfonic acid and $\beta$-cyclodextrin- $\mathrm{SO}_{3} \mathrm{H}$ afforded the target molecule in $<79 \%$ yield (Table 2 , entries $6-10$ ). The temperature had an obvious effect on the reaction: for example, by increasing the reaction temperature from room temperature to reflux, the yield was increased from 41 to $93 \%$ (Table 3, entries 1-4). Reflux temperature was proven to be advantageous and hence it was finalized for obtaining better results. Since solvents play crucial role to expedite the reaction rate, further efforts were diverted to screen the effect of solvents with the hope that reaction time may reduce and product yield may enhance. Subsequently, by changing the solvent to dichloromethane, tetrahydrofuran, dimethylformaamide and dimethylsulfoxide reduced the yields to $48,53,70$ and $62 \%$, respectively (Table 3 , entries 5-8). When water or aq. ethanol (1:1) was used as the solvent, the desired product was obtained in moderate yield (Table 3, entries 9-10).

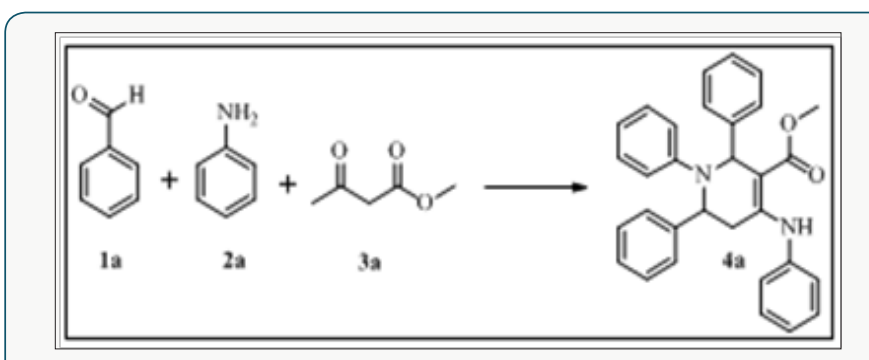

Figure 1: Standard model reaction.

\begin{tabular}{|c|c|c|c|c|c|}
\hline Entry & Catalyst & Concentration (mol \%) & Temperature $\left({ }^{\circ} \mathrm{C}\right)$ & Time (min) & Yieldb (\%) \\
\hline 1 & - & - & RT & 600 & trace \\
\hline 2 & - & - & Reflux & 600 & trace \\
\hline 3 & CSA & 5 & Reflux & 150 & 80 \\
\hline 4 & CSA & 10 & Reflux & 110 & 93 \\
\hline 5 & CSA & 15 & Reflux & 110 & 93 \\
\hline 6 & Sulphamic acid & 10 & Reflux & 110 & 67 \\
\hline 7 & p-TSA & 10 & Reflux & 110 & 79 \\
\hline 8 & Glycine & 10 & Reflux & 110 & 45 \\
\hline 9 & PS-PTSA & 10 (mg) & Reflux & 110 & 70 \\
\hline 10 & $\beta$-cyclodextrin- $\mathrm{SO}_{3} \mathrm{H}$ & 10 & Reflux & 110 & 76 \\
\hline
\end{tabular}

Table 3: Effect of temperature and screening of solvents ${ }^{\mathrm{a}}$

\begin{tabular}{|c|c|c|c|}
\hline Entry & Solvent & Temperature ( $^{\mathbf{C}} \mathbf{)}$ & Yield ${ }^{\mathbf{b}}(\mathbf{\%})$ \\
\hline 1 & Ethanol & RT & 41 \\
\hline 2 & Ethanol & 40 & 59 \\
\hline 3 & Ethanol & 60 & 78 \\
\hline 4 & Ethanol & Reflux & 93 \\
\hline 5 & DCM & Reflux & 48 \\
\hline 6 & THF & Reflux & 53 \\
\hline 7 & DMF & Reflux & 70 \\
\hline
\end{tabular}




\begin{tabular}{|c|c|c|c|}
\hline 8 & DMSO & Reflux & 62 \\
\hline 9 & WATER & Reflux & 84 \\
\hline 10 & Aq. Ethanol (1:1) & Reflux & 80 \\
\hline \multicolumn{2}{|c|}{ aReaction condition: $1 \mathrm{a}(2 \mathrm{mmol}), 2 \mathrm{a}(2 \mathrm{mmol}), 3 \mathrm{a}(1 \mathrm{mmol})$, solvent $(10 \mathrm{ml})$, CSA $(10 \mathrm{~mol} \%), 110$ min; bIsolated yields. } \\
\hline
\end{tabular}

However, when ethanol was used as the solvent, the compound methyl 1,2,6-triphenyl-4-(phenylamino)-1,2,5,6tetrahydropyridine-3-carboxylate 4 a was isolated in 93\% yield (Table 3, entry 4). Thus, the optimal reaction conditions were found to be $10 \mathrm{~mol} \%$ camphor sulfonic acid catalysts with ethanol as the solvent at reflux for $110 \mathrm{~min}$. The scope of this five component reaction under optimized reaction conditions were explored using a variety of aldehydes, anilines and $\beta$-keto ester, as summarized in Table 1. In general, aromatic aldehydes bearing electron-donating or electron withdrawing functional groups at different position reacted with methyl acetoacetate as well as ethyl acetoacetate smoothly in the presence of various anilines to generate the corresponding product in excellent yield. Also, several aromatic amines were examined. Various anilines with substituent such as $-\mathrm{Me},-\mathrm{F},-\mathrm{Cl}$ and $-\mathrm{OMe}$ were treated with varying aromatic aldehydes and $\beta$-keto esters under identical reaction conditions. All these reactions underwent smoothly to provide the corresponding Piperidines derivatives in excellent yields. Formation of the desired product was confirmed with the help of ${ }^{1} \mathrm{H} N M R,{ }^{13} \mathrm{C}$ NMR and mass spectroscopic data. The $1 \mathrm{H}$ NMR spectrum of compound $4 \mathrm{~b}$ showed a singlet at $\delta 6.35 \mathrm{ppm}$ for $-\mathrm{CH}$, triplet at $\delta 5.48 \mathrm{ppm}$ for $-\mathrm{CH}$ and multiple at $\delta 2.96-2.92 \mathrm{ppm}$ for the methylene group.

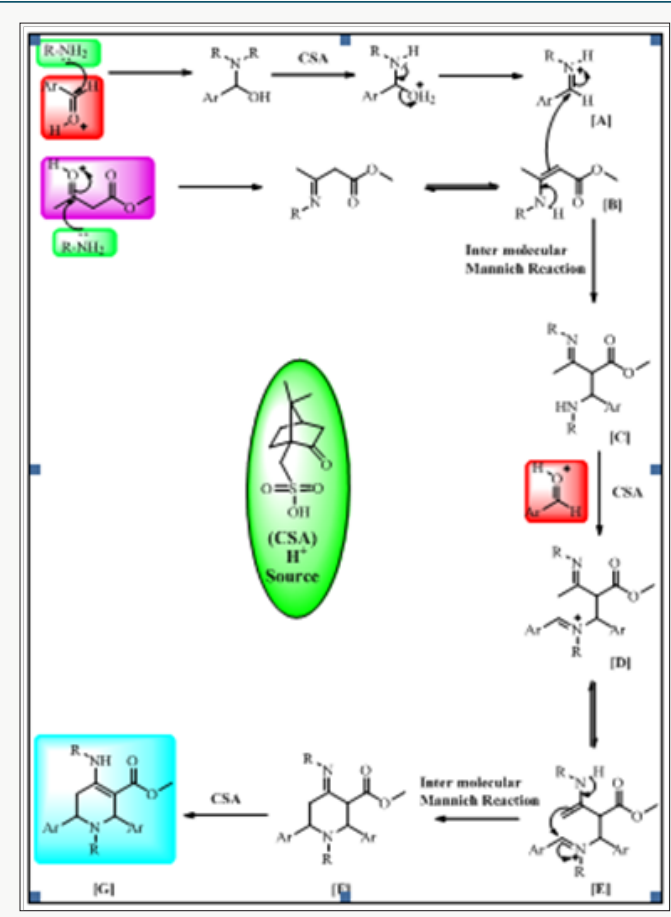

Figure 2: A Plausible mechanism for the synthesis of piperidines.

The presence of four characteristic carbon signals are observed at $\delta 97.6,56.6,51.1,33.4 \mathrm{ppm}$ in ${ }^{13} \mathrm{C}$ NMR spectrum of $4 \mathrm{~b}$ owing to carbons of $\mathrm{C}=\mathrm{C},-\mathrm{CH},-\mathrm{CH}$, and $-\mathrm{CH}_{2}$ groups of the piperidine ring, respectively authorizing the presence of a piperidine ring in $4 \mathrm{~b}$. The mass spectrum of $4 \mathrm{~b}$ further support the structure as it display $[\mathrm{M}+\mathrm{H}]+$ ion peak at $\mathrm{m} / \mathrm{z} 529.2$ in consistent with its molecular formula $\mathrm{C}_{31} \mathrm{H}_{26} \mathrm{Cl}_{2} \mathrm{~N}_{2} \mathrm{O}_{2}$. A plausible reaction mechanism involved in the synthesis of highly substituted piperidines is proposed as shown in Figure 1. On the basis of the proposed mechanism in the literature, it is reasonable to presume that highly substituted piperidine [G] results from initial condensation of $\beta$-ketoester and aromatic aldehyde with aniline in the presence of CSA to give enamine $[\mathrm{B}]$ and imine $[\mathrm{A}]$. Subsequently, enamine [B] reacts with imine $[\mathrm{A}]$ to produce intermediate $[\mathrm{C}]$ through intermolecular Mannich-type reaction. The reaction between intermediate [C] and aldehyde gives intermediate [D] by the elimination of $\mathrm{H}_{2} \mathrm{O}$. Then, tautomerization of [D] generates intermediate [E], which immediately undergoes intramolecular Mannich-type reaction to give intermediate $[\mathrm{F}]$. Finally, this intermediate tautomerizes to generate the desired piperidine derivative [G] owing to conjugation with the ester group (Figure 2).

\section{Conclusion}

In conclusion, we have developed an efficient one pot multi component synthesis of highly substituted Piperidines derivatives using camphor sulfonic acid as the catalyst. A variety of aldehydes were efficiently converted in combination with different type of anilines into various substituted Piperidines in excellent yields. Additionally, different $\beta$-ketoesters gave substituted Piperidines in a straightforward manner. Furthermore, the simple experimental procedures, utilization of an inexpensive and readily available ecofriendly catalyst are the advantages of present methodology. This protocol proceeds with high atom-efficiency and shows a broad substrate scope and functional group tolerance, making it a highly practical approach for preparation of pharmaceutically interesting various Piperidines derivatives.

\section{Acknowledgement}

The Emeritus Scientist Scheme awarded to MSS by the Council of Scientific and Industrial Research, New Delhi is gratefully acknowledge. Thanks to Head, Department of Chemistry, Dr. B. A. M. University, Aurangabad, for providing the laboratory facilities. MAC is grateful to University authorities for financial assistance in the form of University fellowship.

\section{References}

1. (a) AD Elbein, R Molyneux (1987) In Alkaloids Chemical and Biological Perspectives. John Wiley \& Son New York, UK p1-54.

(b) D O'Hagan (2000) Pyrrole, pyrrolidine, pyridine, piperidine and tropane alkaloids. Nat Prod Rep 17: 435. 
(c) JW Daly, TF Spande, HM Garraffo (2005) Alkaloids from amphibian skin: a tabulation of over eight-hundred compounds. J Nat Prod 68: 1556.

2. (a) K Murata, F Takano, S Fushiya, Y Oshima (1998) Enhancement of NO production in activated macrophages in vivo by an antimalarial crude drug, Dichroa febrifuga. J Nat Prod 61: 729.

(b) S Kobayashi, M Ueno, R Suzuki, H Ishitani, HS Kim, et al. (1999) Catalytic asymmetric synthesis of antimalarial alkaloids febrifugine and isofebrifugine and their biological activity. J Org Chem 64: 6833.

(c) $\mathrm{Y}$ Takaya, $\mathrm{H}$ Tasaka, $\mathrm{T}$ Chiba, $\mathrm{K}$ Uwai, $\mathrm{M}$ Tanitsu, et al. (1999) J Med Chem 42: 3163. (d) M Misra, SK Pandey, VP Pandey, J Pandey, R Tripathi, et al. (2009) Organocatalyzed highly atom economic one pot synthesis of tetrahydropyridines as antimalarials. Bioorg Med Chem 17: 625-633.

(e) S Petit, JP Nallet, M Guillard, J Dreux, R Chermat, et al. (1991) Synthèses et activités psychotropes de 3,4-diarylpipéridines. Corrélation structure-activité et recherche d'une activité antihypertensive Synthesis and psychotropic activity of 3,4-diarylpiperidines. Structure-activity relationship and antihypertensive activity. Eur J Med Chem 26: 19-32.

(f) H Bin, AM Grider, JP Stables (2001) Synthesis and structureactivity relationships of potential anticonvulsants based on 2-piperidinecarboxylic acid and related pharmacophores. Eur J Med Chem 36: 265-286

(g)AA Trabaco, N Aerts, RM Alvarez, JI Andres, I Boeckx, et al. (2007) 4-Phenyl-4-[1H-imidazol-2-yl]-piperidine derivatives as non-peptidic selective delta-opioid agonists with potential anxiolytic/antidepressant properties. Part 2. Bioorg Med Chem Lett 17: 3860-3863.

(h) J Kobayashi, M Ishibashi (1996) ChemInform Abstract: Sphingosine-Related Marine Alkaloids: Cyclic Amino Alcohols. Heterocycles 42: 943.

(i) I Ninomiya, T Kiguchi, T Naito (1998) Alkaloids 50: 317.

(j) RF Boswell,WJWelstead, RL Duncan, DN Johnson, WH Funderburk (1978) (1-(3-(Phenothiazin-10-yl) propyl)-4-piperidinyl)phenylmethanones, a novel class of long-acting neuroleptic agents. J Med Chem 21: 136-139.

3. WC Van Voorhis, KL Rivas, P Bendale, L Nallan, C Horney et al. (2005) Protein farnesyltransferase inhibitors exhibit potent antimalarial activity. J Med Chem 48: 3704-3713.

4. J Aboonajmi, M Safarzaei, E Fereidooni, S Sajadikhah (2012) Res Pharm Sci 7: 546.

5. (a) CF Barbas (2008) Die verlorene Organokatalyse: moderne Chemie, klassische Chemie und ein unbemerkter Biosynthesemechanismus. Angew Chem 120: 44-50.

(b) CF Barbas (2008) Organocatalysis lost: modern chemistry, ancient chemistry, and an unseen biosynthetic apparatus. Angew Chem Int Ed 47: 42-47.

(c) S Bertelsen, KA Jorgensen (2009) Organocatalysis-after the gold rush. Chem Soc Rev 38: 2178.

6. PI Dalko, L Moisan (2004) In the Golden Age of Organocatalysis. Angew Chem Int Ed 43: 5138-5175.

7. (a) PV Shinde, BB Shingate, MS Shingare (2011) An Organocatalyzed and Ultrasound Accelerated Expeditious Synthetic Route to 1,5-Benzodiazepines under Solvent-Free Conditions. Bull Korean Chem Soc 32: 1179-1182.

(b) PV Shinde, AH Kategaonkar, BB Shingate, MS Shingare (2011) An organocatalyzed facile and rapid access to $\alpha$-hydroxy and $\alpha$-amino phosphonates under conventional/ultrasound technique. Tetrahedron Lett 52: 2889-2892.

8. (a) M Makoto, H Yamamoto (1995) 68 (1995): 2657.

(b) A Gayet, C Bolea, PG Andersson (2004) Development of new camphor based N,S chiral ligands and their application in transfer hydrogenation. Org Biomol Chem 2(2004): pp1887.

(c)BK Gorityala, S Cai, J Ma, X Liu (2009) (S)-Camphorsulfonic acid catalyzed highly stereoselective synthesis of pseudoglycosides. Bioorg Med Chem Lett 19: 3093-3095.

(d) AGM Barrett, D Braddock, PWN Christian, D Pilipauskas, AJP White et al. (1998) Org. Chem. 63: 5818.

(e) Sejin, K Gijung, K Narae, SE Shim, C Soonja (2005) The effect of camphorsulfonic acid in TEMPO-mediated bulk and dispersion polymerization of styrene. Macromol Res 13:187-193.

9. TP Lebold, AB Leduc, MA Kerr (2009) A Zn(II) Catalyzed Synthesis of Piperidines from Propargyl Amines and Cyclopropanes. Org Lett 11: 3770-3772.

10. (a) K Takasu, N Shindoh, H Tokuyama, M Ihara (2006) Catalytic Imino Diels-Alder Reaction by Triflic Imide and Its Application to One-pot Synthesis from Three Components. Tetrahedron 62: 11900-11907.

(b) $\quad M$ Sales, AB Charette (2005) A Diels-Alder approach to the stereoselective synthesis of 2,3,5,6

tetra- and 2,3,4,5,6-pentasubstituted piperidines. Org Lett 7: 5773-5776.

11. (a) MSR Murty, R Ram, JS Yadav (2008) $\mathrm{BiCl}_{3}$ promoted aza-Prins type cyclization: a rapid and efficient synthesis of 2,4-disubstituted piperidines. Tetrahedron Lett 49: 1141-1145.

(b) RM Carballo, MA Ramirez, ML Rodriguez, VS Martin (2006) Iron(III)-Promoted Aza-Prins

Cyclization: Direct Synthesis of Six-Membered Azacycles. JI Padron Org Lett 8: $3837-3840$

(c)AP Dobbs, SJ Guesne (2005) Rapid Access to trans-2,6-Disubstituted Piperidines: Expedient Total Syntheses of (-)-Solenopsin A and (+)-epiDihydropinidine. J Synlett 13: 2101-2103.

12.S Fustero, D Jimenez, J Moscardo, S Catalan (2007) C Del Pozo Org Lett 9: 5283.

13. FA Davis, B Chao, A Rao (2001) Org Lett 3: 3169.

14. T Boehm, W Stocker (1943) Archiv der Pharmazie 281: 62.

15. (a) PA Clarke, AV Zaytsev, AC Whitwood (2007) Pot, atom and step economic (PASE) synthesis of highly functionalized piperidines: a fivecomponent condensation. Tetrahedron Lett 48: 5209-5212.

(b) PA Clarke, AV Zaytsev, AC Whitwood, Synthesis (2008) Pot, Atom, and Step Economic (PASE)

Synthesis of Highly Substituted Piperidines: A Five-Component Condensation. Synthesis 21: 3530-3532.

16. AT Khan, T Parvin, LH Choudhury (2008) Effects of substituent in $\beta$-position of 1, 3-Dicarbonyl Compounds in Bromodimethylsulfonium Bromide Catalyzed Multicomponent Reactions: A Facile Access to Functionalized Piperidines. J Org Chem 73: 8393-8402.

17. AT Khan, M Lal, Md M Khan, KKR Bannuru (2010) Synthesis of highly functionalized piperidines by one-pot multicomponent reaction using tetrabutylammonium tribromide (TBATB). Tetrahedron Lett 51: 44194424.

18. AT Khan, Md M Khan, KKR Bannuru (2010) Iodine catalyzed one-pot five-component reactions for direct synthesis of densely functionalized piperidines. Tetrahedron 66: 7762-7772.

19. N Agrawal, S Bahekar, P Sarode, S Zade, H Chandak (2015) L-Proline nitrate: a recyclable and green catalyst for the synthesis of highly functionalized piperidines. RSC Adv 5: 47053-47059.

20.S Verma, S Kumar, SL Jain, B Sain (2011) Thiourea dioxide promoted efficient organocatalytic one-pot synthesis of a library of novel heterocyclic compounds. Org Biomol Chem 9: 6943-6948. 
21. (a) JB Gujar, MA Chaudhari, DS Kawade, MS Shingare (2014) Sodium chloride: a proficient additive for the synthesis of pyridine derivatives in aqueous medium. Tetrahedron Lett 55: 6939-6942.

(b) VB Labade, PV Shinde, MS Shingare (2013) A facile and rapid access towards the synthesis of 2,3-dihydroquinazolin-4(1H)-ones. Tetrahedron Lett. 54: 5778-5780. (c) MA Chaudhari, JB Gujar, DS Kawade, PV Shinde, MS Shingare (2015) $\beta$-Cyclodextrin- $\mathrm{SO}_{3} \mathrm{H}$-catalyzed facile and highly efficient synthesis of 4-thiazolidinones under solvent free conditions. Res Chem Inter 41: 10027-10035.

\section{(C) \\ This work is licensed under Creative Commons Attribution 4.0 License}

To Submit Your Article Click Here: $\quad$ Submit Article

DOI: $10.32474 /$ AOICS.2018.01.000113

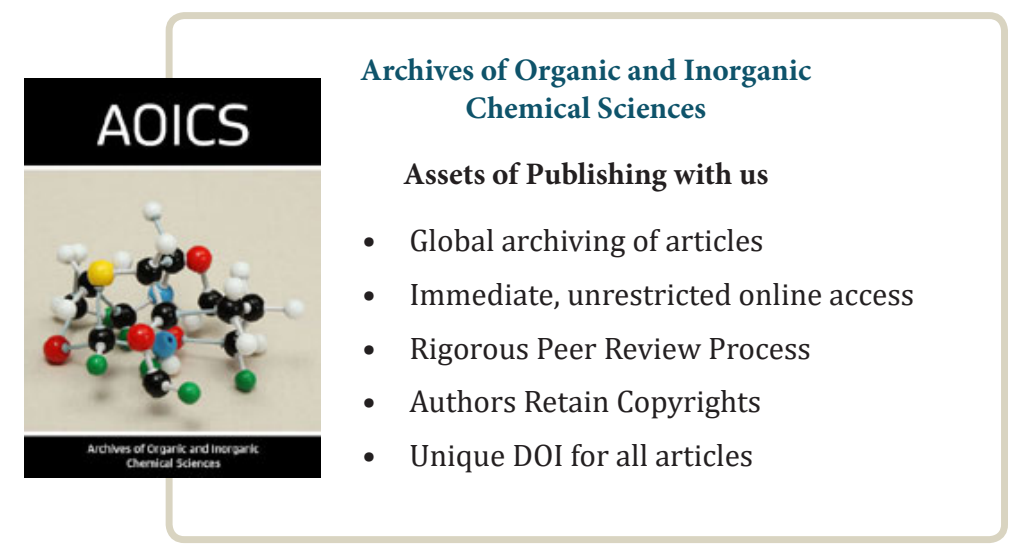

